\title{
Exploring teachers' increased knowledge of the potential of mobile phone use: pilot study reducing the difference between students' and teachers' ideas
}

\author{
Tiina Leino Lindell $^{1}$ (1D
}

Received: 29 October 2019 / Accepted: 13 February 2020/ Published online: 27 February 2020

(C) The Author(s) 2020

\begin{abstract}
It has been emphasized that students and teachers have dissimilar ideas about how mobile phone use could be utilized and limited. Moreover, these differences have been identified as a crucial problem that has caused conflicts in education. In order to resolve the problem, research has stressed that it is very important to increase teachers' knowledge about how mobile phones can be used in students' work. However, the topic of how teachers could increase their understanding related to students' ideas has remained largely unexamined. Thus, this pilot study explores the following research questions using cultural-historical activity theory and qualitative methods: How is teachers' possibility knowledge influenced when they are exposed to students' ideas about how mobile phones could be both supportive and problematic in school activities? What are the similarities and differences between the students' ideas that have, and have not, influenced the teachers' possibility knowledge of mobile phone use? The results show how the teachers' possibility knowledge increases concerning the features that could be both supportive and problematic and must be limited by rules and a division of labor. Moreover, it transpires that the teachers' possibility knowledge is not always affected. It appears that the teachers' understanding is influenced if they can relate the students' ideas to the teachers' division of labor. These results could be used by schools to resolve problems caused by the different ideas of students and teachers regarding mobile phone use. The results could also be used when implementing mobile phones in educational research.
\end{abstract}

Keywords Teachers' possibility knowledge $\cdot$ Mobile phone features $\cdot$ Student-centered design $\cdot$ Cultural-historical activity theory

Tiina Leino Lindell

Leino@kth.se

1 The Digital Learning unit at the department of Learning, KTH Royal Institute of Technology, SE-100 44 Stockholm, Sweden 


\section{Introduction}

For some time now, it has been observed that students' and teachers' ideas regarding the use of mobile phones have great significance in school activities (Chai et al. 2017; Kim and Jang 2015). However, several studies have emphasized that students and teachers have dissimilar ideas regarding mobile phone use and regulations. Additionally, these differences have been identified as being a crucial problem that has caused conflicts in school activities (Ariel and Elishar-Malka 2019; Dinsmore 2019; MuñozCristóbal et al. 2017). Even though the different ideas of teachers and students have had a problematic impact on education, it is remarkable that there has been hardly any research that has examined how these problems could be reduced. (Dinsmore 2019; Muñoz-Cristóbal et al. 2017). Ariel and Elishar-Malka (2019) point out that it is very important that such differences are reduced. As a solution, they suggest that teachers must increase their knowledge of how mobile phones could be used as a support by students. They also point out that teachers must realize how mobile phone use can be problematic. Several studies have underlined the need for more qualitative research on how teachers' knowledge of mobile phone use could be increased in a design process (Chai et al. 2017; Crompton et al. 2017). Similarly, Hsieh and Tsai (2017) have established that it is necessary to increase sophisticated knowledge of mobile phone use among teachers. Research has also underlined the importance of integrating mobile phones from a student perspective (Khaddage et al. 2015). For example, KukulskaHulme and Traxler (2007) stress that it is important to understand what features are most suitable in order for students to achieve successful use of mobile phones. Nevertheless, student-centered research projects are rare. In a review of published research in journals from 1993 to 2013, Sung et al. (2017) emphasized that there have only ever been a few student-centered projects on this particular subject. They noted that mobile phones have often been used to motivate students and strengthen their engagement in school tasks. Osakwe et al. (2017) state that most studies have investigated how students have used mobile phones for school tasks without considering the teachers' and students' expectations and thoughts. In order to identify solutions to problems caused by the dissimilar ideas of teachers and students, this article focuses on exploring how teachers' understanding related to students' ideas could be increased. The pilot study examines a design process in which teachers are exposed to students' ideas on how mobile phones could be both supportive and problematic in school activities. In this way, the pilot study investigates how the teachers' knowledge is influenced by the students' suggestions. In addition, it explores the similarities and differences between the students' ideas that have, and have not, influenced the teachers' knowledge of mobile phone use. Thus, this pilot study contributes to understanding of how teachers' and students' ideas of mobile phone use can be more aligned, which has been requested.

\section{Literature review}

The literature review first presents recent research on teachers' and students' different ideas regarding mobile phone use. Secondly, the review describes research that highlights what could influence teachers to increase their knowledge of mobile phone use in 
school activities. This means, on the one hand, teachers' increased knowledge of how mobile phones could be used as support for students and, on the other hand, increased knowledge of the problems that students' mobile phone use could lead to and how rules and a division of labor could limit such problems.

\subsection{Different ideas of mobile phone use}

It has been found that teachers and students have different ideas about how mobile phones could be used supportively but are also problematic in school activities (Ariel and Elishar-Malka 2019). Although students use mobile phones for their schoolwork, teachers can regard this as a distraction (Ott et al. 2018). Additionally, many teachers are worried that students' mobile phone use could cause problems. Thus, some teachers advocate strict regulation, and teacher-driven use (Dinsmore 2019). In contrast, a teacher-centered division of labor and its rules against mobile phone use risk leading to significant opposition from students (Dinsmore 2019; Fernandez 2018; Gentina et al. 2018; Ott et al. 2018). This is because students might consider that mobile phones are useful for their schoolwork (Fernandez 2018; Ott et al. 2018). Muñoz-Cristóbal et al. (2017) discovered that although students want rules against disruptive use, they do not support strict mobile phone regulations. Instead, it is common for students to use their mobile phones despite their teachers' rules (Joyce-Gibbons et al. 2018; Nikolopoulou and Gialamas 2018; Ott et al. 2018).

\subsection{Teachers' increased knowledge of supportive mobile phone use}

Previous research has found that teachers' knowledge of how mobile phones could support students is influenced by their experiences. For example, O'Bannon and Thomas (2015) stated that teachers' experiences could increase their knowledge of what features are useful for students' work. Teachers' could also increase their understanding if they have practiced that students' mobile phone use is pleasant, stimulating and enjoyable (Adukaite et al. 2017). Several studies underline that teachers' personal use and practice result in greater knowledge of how students could use mobile phones for educational objectives (O'Bannon and Thomas 2015; O'Neill et al. 2018). O'Neill et al. (2018) discovered that teachers' knowledge is more influenced by their personal objectives than ideas on how mobile phones could be used for didactic purposes. Furthermore, teachers' experiences of using mobile phones in educational settings that conform to the syllabus indicate that mobile phones can be used supportively by students (Adukaite et al. 2017; Hsieh and Tsai 2017). Hsieh and Tsai (2017) have also seen how teachers' experiences of students' mobile phone use have influenced their understanding of how mobile phones could support students' group work. For instance, by enabling online work on the same task from multiple locations. Similarly, Zurita and Nussbaum (2007) noted that students networking with mobile devices at multiple locations influenced the teachers' ideas that mobile phone use could increase the students' interest in carrying out school tasks. Kearney et al. (2015) argue that students' personal ownership of mobile phones is positively associated with online discussions. These types of school activities can also influence teachers' knowledge that mobile phones could provide realistic and discipline-specific support for the students' schoolwork. However, they noted that teachers largely design activities for face-to-face 
contexts and have not understood how they could utilize the opportunities that networked mobile phone use could provide. Several studies also emphasize that teachers' understanding could be increased through teacher education (Adukaite et al. 2017; Birgin et al. 2019; Hsieh and Tsai 2017). For example, education could enable teachers to understand how they could change their pedagogy in order to integrate mobile phone use into school activities (Khaddage et al. 2015; Peng et al. 2009). Similar, O'Neill et al. (2018) discuss the possibility of increasing teachers' understanding by showing them effective ways of using mobile phones for education.

\subsection{Teachers' increased knowledge of problematic mobile phone use}

Sung et al. (2017) have discussed how vague rules and division of labor could cause problems in students' school activities with mobile phones. To overcome such problems, students' off-task behavior should be reduced through a division of labor, increasing teacher control. They argue that teachers could increase their awareness through more technology-based assistance, which could also support teachers in designing tasks. O'Bannon and Thomas (2015) have noted an increased concern about potential problems among teachers. A possible consequence may be increased access to mobile phones since such access gives teachers an experience of defining mobile phone use problems, they argue. However, the teachers' concerns those mobile phones could be distracting or used inappropriately for bullying or cheating result in their understanding that mobile phones should be strictly regulated in schools (Joyce-Gibbons et al. 2018; Nikolopoulou and Gialamas 2018; O'Bannon and Thomas 2015). Dinsmore (2019) has noted how teachers' concerns influence their ideas regarding limited mobile phone use. This is because the teachers' concerns have created the desire to control the students' mobile phone use. One way that teachers control students is a division of labor in which teachers store students' mobile phones in boxes. Another way is to increase teacher supervision in the classroom. Joyce-Gibbons et al. (2018) suggest that teachers' resistance could change if they are given the opportunity to discuss how mobile phones could be used as a support, as well as the problems that this may cause. They emphasize that teachers need a "framework" to relate to in order to increase their knowledge.

\section{Aim and research question}

In order to identify solutions to problems caused by the different ideas of mobile phone use of teachers and students, it is important to gain more knowledge about the problems. This pilot study aims to explore how teachers' understanding is influenced by students' ideas in order to promote a student-centered design in school activities. In other words, this pilot study examines how teachers' possibility knowledge increases when they are exposed to students' ideas. The concept of possibility knowledge includes teachers' ideas about how students' use of different mobile phone features could support their own tasks and the teachers' tasks. Possibility knowledge also includes teachers' ideas of how using different features could create problems and how these could be limited. Furthermore, the aim was to examine the patterns of similarities and differences between the students' ideas that have, and have not, increased the teachers' possibility knowledge. 
- How is teachers' possibility knowledge influenced when they are exposed to students' ideas on how mobile phones could be both supportive and problematic in school activities?

- What are the similarities and differences between the students' ideas that have, and have not, influenced the teachers' possibility knowledge of mobile phone use?

\section{Theoretical stance}

This pilot study has applied Cultural-historical activity theory (CHAT) in order to meet the study's aim and answer the research question. CHAT is a theory that has been emphasized as being valuable in facilitating peoples' understanding and transformation of activities (Hakkarainen 2009; Timmis 2014). Moreover, the theory has been previously used to understand how conflicts between people can change (Engeström 1987, 2004; Engeström et al. 2005) and is a well-established theory that has long proven it usefulness. It has been acknowledged for the opportunity it provides to understand activities that implement mobile phones (Chung et al. 2019; Sung et al. 2017; Zurita and Nussbaum 2007). CHAT is a dialectical approach, meaning that processes and transformations are key issues. It is believed that people both develop their history and are also a consequence of it. From the CHAT perspective, the study participants are regarded as agents. This means that the transformation of activities is governed by the participants' ability and willingness to shape activities (Engeström and Sannino 2016).

However, criticism has been directed towards CHAT because of concerns regarding potential broad generalizations from local experiments (Ellis et al. 2015). However, Engeström et al. (2014) argue that instead of running through large patterns we must cultivate preventive solutions through local experiments. We can then generalize and disseminate knowledge through dialog and further experiments.

\subsection{Teachers' possibility knowledge of supportive mobile phone use}

CHAT assumes that teachers' and students' understanding manifests in ideas of how they want to use mobile phones in future school activities. Sannino and Engeström (2017) describe people's understanding using the concept of possibility knowledge. Possibility knowledge manifests as future-oriented visions and designs. Thus, the concept embraces people's knowledge of what could be potentially new forms of activity. In other words, possibility knowledge includes teachers' ideas of how mobile phones could be both supportive and problematic in future school activities. In CHAT, the participants' visions of an activity that they will actualize in the future is the same as an activity object (Engeström and Sannino 2010; Sannino et al. 2016). A collective activity is driven by a common motive that responds to a common need and object (Engeström 2000; Engeström 1999). The object is strongly connected with human desires and needs (Sannino et al. 2016). For example, students can express visions that tools, such as video features on mobile phones, should be used to facilitate their division of labor when they are solving school tasks. The division of labor is a component that refers to how individuals, such as teachers and students, in a collective activity, distribute work between themselves when they are operating to achieve the activity object (Engeström 1990; Engeström and Sannino 2010). When teachers and 
students describe their needs of how mobile phone features can be used to support their division of labor, this also means that they have described their possibility knowledge of how mobile phone use could support the object of the school activity (Engeström 2000; Engeström and Sannino 2010; Sannino et al. 2016).

\subsection{Teachers' possibility knowledge of problematic mobile phone use}

When activities are developed, it is important to identify and define problems in the initial stage of the process (Engeström 2000). CHAT can offer knowledge of what kind of mobile phone use the teachers and students regard as being problematic. CHAT can also highlight the problems that teachers and students think should be limited through rules and a division of labor (Engeström and Sannino 2010). It is particularly important to be able to elucidate how problems regarding mobile phone use can be regulated in educational contexts. One reason for this is that students may have nomophobia, which is the fear of being out of contact with a mobile phone (Dixit et al. 2010; Lorenzo and Trujillo 2018; Yildirim et al. 2016). Rules refer to norms that may limit the participants' actions (Engeström 1990; Engeström and Sannino 2010). If new tools, including mobile phone features, are introduced, this will influence the rules and the division of labor in an activity. In other words, these components are interrelated (Engeström 2011).

\subsection{Teachers' increased possibility knowledge of mobile phone use}

If the participants have different possibility knowledge of how an activity could develop, it creates a problematic situation since there is a conflict of motives (Sannino and Engeström 2017). In such cases, the conflict of motives manifests through the students' and teachers' different ideas regarding potential mobile phone use, for example, their different ideas regarding the mobile phone features they want to use, and for what objective. Within CHAT, conflicts of motives play a key role in formative interventions because conflicts of motives can be used as stimuli to increase people's possibility knowledge. At this point, the students' ideas on supportive and problematic mobile phone use could function as stimuli. This stimulation is the basic mechanism that engenders a new willingness among the participants (Engeström et al. 2014). Artifacts, signs and theoretical components can then be used as stimuli to change problematic situations (Engeström 2011). Thus, formative interventions in CHAT are understood to be a dialectical design-based methodology.

\section{Method}

\subsection{Research context}

This research project relates to a study visit activity in which teachers and ninth grade students at a Swedish lower secondary school visited an upper secondary school. This is a formal school activity, which is performed as part of the lower secondary school's technology education. One reason for the study visit was that the lower secondary school lacks technological resources. Over the course of a day, the students got to work 
with computer-aided design, computer numerical control, mathematical problem-solving, control systems and product development based on solving everyday problems. The study visit is appreciated but has also been perceived as problematic. Teachers felt that the study visit was not connected to teaching before or after. In order to make future study visit activities more useful, the teachers stated that there was a need to develop new ways of experiencing them.

The results of previous studies in the project show that teachers and students agreed that students should work collaboratively in smaller groups of 3-4 with mobile phones. They also agreed on a rule stating that students should only use their mobile phones for school tasks. However, the results showed that the teachers and the students had different ideas of how mobile phone features can be used to offer support, and how such features can cause problems. Compared to the teachers, the students expressed a wider range of ideas on how features provide support or cause problems. Some of the students also had ideas about how problems could be regulated using a division of labor (Lindell and Hrastinski 2018).

\subsection{The participants}

The participants in the pilot study comprise two teachers and seven students: two boys and five girls. The research aim and question are based on a representative sample selection, in which teachers and students have different ideas about how mobile phones could be both supportive and problematic in school activities. As previously described, previous studies in the project have shown that the teachers and students have different ideas on the topic. Previous studies have also shown that every teacher and student has experienced that mobile phone use creates conflicts. They stated that there have been conflicts between the students' mobile phone use and the teachers' applied rules (Lindell 2018). The selection of teachers in this pilot study is the same as in previous studies. Similarly, the students' ideas that were used to stimulate the teachers are also the same as the ideas that were collected and presented in previous studies (Lindell and Hrastinski 2018; Lindell 2018). Thus, the selection of participants for this pilot study is representative of the problem being investigated. Hence, there is no risk of implications from non-participation and gaps in coverage for this pilot study (Tong et al. 2007; Twining et al. 2017). In this way, the participants in this pilot study have been chosen for the diversity of their experiences and their connection to the issue at hand (Hamel 2001). Thus, the selection of participants is typical and representative of the aim and research question (Hamel 2001; Spencer et al. 2003; Twining et al. 2017).

The initial sampling method for this research project has been made using purposive sampling (Cohen et al. 2007). This means that the participants have been chosen with specific criteria in mind. One criterion was that the participants who were part of the selection should have taken part in the school activity to which this pilot study relates. The selection for the pilot study was therefore made with the ongoing study visit as reference. On the spot, a convenience sample method was conducted among participating students during the study visit activity. As a result, the first class of students to arrive was invited to participate (Denscombe 2014). A group of 13 students were informed about the pilot study and asked if they wanted to participate. Another criterion was connected to ethical guidelines, meaning the students had to have the written consent of their parents. All seven students who submitted written consent joined the 
pilot study. When selecting the teachers, it was similarly important that they also had experience of the activity. Both teachers who accompanied the students from the school were asked to participate.

\subsection{Data collection}

The data collection process was systematized based on formative interventions. In order to meet the research aim and answer the questions, it was important to create conditions for collecting data that demonstrated how the teachers' possibility knowledge is influenced when they are exposed to students' ideas. Thus, the data collection included data on students' ideas on mobile phone use, as well as teachers' ideas before and after they were exposed to the students' ideas.

Data were collected on four occasions: twice with two different student groups and twice with a group comprising two teachers. During the process, it was important to separate students and teachers in order to increase the students' participation in the groups, and to avoid hierarchies that could influence the answers in a group discussion (Stewart \& Shamdasani 2014). The students were also divided into two groups to enable triangulated data, thereby increasing the credibility of the pilot study (Elliott et al. 1999; Mathison 1988). One group comprised four students (two girls and two boys) and the other comprised three girls. A mentor teacher with overall responsibility for the class divided the students into groups. The mentor teacher was not one of the two teachers chosen for the pilot study. Data collection was performed in the following order: Data 1, containing data on the teachers' initial ideas about mobile phone use. Data 2, including ideas from student group 1 and Data 3, ideas from student group 2. Finally, Data 4 contained data from the teachers' ideas when they were exposed to the students' ideas.

In order to investigate the aim and answer the research question, a nominal group technique (Delp et al. 1977; Horton 1980) and a Delphi technique (Ven and Delbecq 1974) were combined. The nominal group technique was used to collect data when the teachers and students expressed their initial ideas on how different mobile phone features could be used to support the teachers' and students' division of labor. This technique was also used for data collection of how the use of different features creates problems and how such issues could be limited through rules and a division of labor. In other words, the method was used to enable the participants to express their possibility knowledge of how mobile phones could be both supportive and problematic in school activities. Parts of the Delphi technique have been subsequently adopted. The method has been used to collect data on how teachers increase their knowledge when they are exposed to the students' ideas. Together, the methods add credibility to the pilot study through method triangulation since it provides both written and oral expressions and arguments about how mobile phones could be both supportive and problematic in school activities (Elliott et al. 1999; Mathison 1988; Yin 2013). In addition to the written suggestions relating to nominal group technique, audio recordings were also used as an instrument of data collection. This is because it provides access to more detailed data on the participants' articulated ideas than the researcher's notes (Tong et al. 2007).

The nominal group technique and the Delphi technique The nominal group technique was chosen to provide the opportunity to collect data when teachers and students expressed their ideas about what kind of mobile phone features could be used for a 
specific school activity. This is a method that has been developed for generating ideas by letting participants express ideas both individually and in dialogue (Delp et al. 1977; Horton 1980). Certain procedures apply when using this method. In this pilot study, teachers' and students' initial ideas were collected via the following procedure recommended by Horton (1980): First, all participants were given quiet time to think of ideas. Second, they were asked to think about the mobile phone features they would like to use and for what objectives and, finally, their preferred division of labor. They also had to think on the kinds of problems that using different features could cause and how rules and a division of labor could limit such problems. Following this, their ideas about mobile phone features, rules and division of labor were recorded in individual written notes. The next step was an open discussion and evaluation of the written ideas in the groups. The potential problems and the participants' desire to limit them were then discussed through targeted questions about this topic.

The distinction between teachers and students during the data collection procedure is why parts of the Delphi technique were adopted for the method. The Delphi technique has been used in previous research to summarize the participants' reasoning in questions, even when not everyone was physically present (Ven and Delbecq 1974). By adopting the Delphi technique, the teachers in this pilot study had the opportunity to be exposed to the students' ideas, without being in physical contact. The students' written suggestions from the nominal group technique were then used to serve as a stimulus. Use of the students' own written suggestions has credibility as it gives the students control over their formulations (Tong et al. 2007). In other words, the written suggestions functioned as a direct stimulus from the students, without being transcribed and interpreted by the researcher. First, the written ideas regarding the mobile phone features they wanted to use and, for what objectives, were presented. The written proposals on rules and division of labor were then presented. The researcher presented the discussed problems verbally to the teachers in connection with the proposals on rules. Dalkey and Helmer (1963) state that the Delphi technique has achieved good results in formulating ideas. The technique has also been discussed as a possible method of developing and evaluating mobile phone use in school activities (Kukulska-Hulme and Traxler 2007).

\subsection{Data analysis}

The analysis was carried out in three different stages, which together meet the aim and answer the research question.

Analysis 1 analyzed the teachers' stated possibility knowledge before and after they were exposed to stimuli from the students' ideas. Thus, the first analysis focused on which features the teachers wanted the students to use, for what objective and how mobile phone use was expected to support the students' and teachers' division of labor for the activity. The potential problems the teachers described regarding the students' use of mobile phone features were then analyzed, as well as how the teachers wanted the problems to be limited by means of rules and a division of labor. The analysis was performed twice, once in analysis 1a made on Data 1 (comprising data before the teachers were exposed to the stimuli) and once in analysis 1b on Data 4 (comprising data after the teachers were exposed to the stimuli). 
Analysis 2 compared the results from analyses $1 \mathrm{a}$ and $1 \mathrm{~b}$, i.e. the teachers' possibility knowledge was compared before and after they were exposed to the stimuli from the students' ideas. If the comparison showed new possibility knowledge in Data 4 compared to Data 1, this was interpreted as increased possibility knowledge among the teachers. As a result, analyses 1 and 2 together answer the first research question.

Analysis 3 was based on analysis 2 and examined patterns of similarities and differences between the students' ideas that have, and have not, influenced the teachers' possibility knowledge. Firstly, the students' ideas that had increased the teachers' possibility knowledge were analyzed. This included an analysis of how the students' ideas had stimulated the teachers' possibility knowledge, i.e. the similarities in how the teachers transformed the students' ideas were analyzed. The analysis then highlighted the similarities in the teachers' ideas of how different mobile phone features could support the division of labor. The analysis also highlighted similarities in the teachers' ideas of how different features create problems, and how rules and division of labor could limit such problems. Secondly, the students' ideas that did not increase the teachers' possibility knowledge were analyzed. Thirdly, similarities in the students' ideas of how different features could support the division of labor were analyzed. Also, similarities in the students' ideas of how mobile phone use create problems and how these could be limited by rules and division of labor were analyzed. Fourthly, the analysis compared the differences between the students' ideas that have, and have not, influenced the teachers' possibility knowledge. Thus, analysis 3 answers the second research question.

\subsection{Ethical considerations}

This pilot study complies with current research ethics laws and guidelines (Swedish Research Council 2019). This means that participation was voluntary and all participants were informed about the objective of the research before commencing the study. In order to allow volunteer students to participate, the informed consent of guardians was also required. The participants were anonymized, meaning the names used in the article are fictitious. Moreover, research data are not accessible to unauthorized persons. The role of the researcher has been to inform participants and to systematically collect, transcribe and analyze the data. Since the pilot study's design has been based on CHAT as a theoretical methodology, the risk of unconscious impact from the researcher has been minimized in this pilot study. There is, however, a conscious influence from the researcher because the data collection and analysis are based on a given logic rooted in formative interventions (Engeström et al. 2014).

\section{Results}

\subsection{The influence on teachers' possibility knowledge}

The teachers' increased, and not increased, possibility knowledge of supportive mobile phone use When the teachers were exposed to the students' suggestions about possible use of mobile phone features, this increased their possibility knowledge on three occasions. The first occasion was when they considered the ideas from student group 2 , including students using mobile phones to communicate their experiences with each other 
from different locations. The students suggested that they could make video recordings during the study visits and then share them with students who were unable to participate. The students also proposed that the school's learning management system (LMS) could be used to share photos and notes from the study visits with other students in the class after the visit. Previously, the teachers have not proposed that video recordings should be used to enable students to share their experiences from study visits with students who were not present. Nor did they suggest that photographs, notes and material from the study visits could be shared with the class via the school's LMS. After the teachers were exposed to the students' suggestions, they supported them (see Excerpt 1).

The second time the teachers increased their possibility knowledge was when they considered the suggestions from students in group 2 and group 1. According to the students' ideas, sharing experiences from the study visit with the rest of the class by using photographs could be supportive for the students. Besides, the students in group 2 suggested that they could add these photographs to a presentation program later in order to communicate their experiences (see Excerpt 2).

As a reaction to the students' suggestions, the teachers stated that the students' documentation combined with presentation features could be used in the activity. By allowing students to use mobile phones to document and present their experiences of the study visit, the teachers stated that mobile phone use could support their task of rating the students. Since the teachers have a role in the division of labor whereby they are unable to join the students for the entire study visit, they value the fact that the students' suggestions would improve the activity. Thus, the teachers suggested that the use of such mobile phone features could support a new way of working in future study visits (see Excerpt 3).

The teachers also continued to discuss how they would like to create a new task for the students. The teachers then expressed a wish to design a task in which students should use their mobile phones to communicate their experiences of the study visit. The teachers realized that they would receive significant support when grading the students' work if they designed a task that enabled the students to communicate their experiences via a mobile phone (see Excerpt 4). This is the third time that the teachers increased their possibility knowledge of how the students' mobile phone use could support school activities.

However, the teachers did not respond when they were exposed to the suggestions from student group 1 . These students suggested that they could use notes and a calendar to help them remember what needed to be done. Information retrieval could be used by students to understand difficult concepts and mobile phone features for translation could help them understand difficult English concepts in computer-aided design software. Moreover, the students proposed that calculators could make it easier for them to understand mathematical problems. The teachers did not even respond to the students' statements in group 2, suggesting that to remember the study visits and important dates better, they could use video, photographs, notes, and calendars.

Excerpt 1 Teachers' increased their possibility knowledge when they were exposed to the students' ideas of supportive mobile phone use

\footnotetext{
Researcher: [reads aloud from a post-it note] If someone has been ill, someone in the student group can video record the lessons and share the film with that person. Create a group with the class on the school portal [the LMS] that students can use to exchange photographs, notes and materials.

Johanna: Oh yes!
} 
Excerpt 2 Students' ideas on how different mobile phone features can be used supportively.

$\begin{aligned} & \text { Note from student } \\ & \text { group 1: }\end{aligned}$
$\begin{aligned} & \text { Note from student } \\ & \text { group 2: }\end{aligned}$
$\begin{aligned} & \text { Take pictures, because then you will remember things better. Then you can add the } \\ & \text { pictures to a PowerPoint file and tell the class later what you have done. }\end{aligned}$

The teachers' increased, and not increased, knowledge of problematic mobile phone use On two occasions the teachers also increased their possibility knowledge of mobile phone features that could be problematic. The first occasion was when the teachers considered the student group 2 suggestions that the LMS could support the students' communication. The teachers then described a new concern that had not been previously mentioned. They were concerned that students could video record teachers in unsuitable circumstances during an activity and spread such recordings from the LMS through social media. At this point the teachers expressed a sense of insecurity regarding which persons could access such information via the system. Thus, in order to avoid a potential integrity problem the teachers stated that it was important for them to investigate how files are saved and shared on the LMS before they would allow them to be used (see Excerpt 5).

The second time the teachers increased their possibility knowledge of what could be problematic was when they were exposed to the students' ideas about what problems they wanted to regulate. When the teachers considered the students' proposals concerning problematic mobile phone features, they responded to the students' description in group 2. The students had claimed that it could be problematic if they took photos or made a video recording of someone who did not want to be photographed or video recorded. In order to reduce this risk, most of the students in the group suggested that the teachers should store the students' mobile phones when they were not being used (see Excerpt 6).

This idea influenced the teachers to increase their possibility knowledge of the desired rules and the division of labor. The teachers stated that they did not want the students to have access to their mobile phones all the time. This was suggested as a measure that could limit the risk of teachers being recorded on video. Following this, the teachers suggested a division of labor in which the teachers should regulate the students' access to mobile phones, i.e. the teachers should store the students' mobile phones until they needed to be used (see Excerpt 7).

However, the teachers only suggested these rules for video recording and not for taking photos which, according to the students in both groups, could also create similar problems. In addition, the teachers did not increase their possibility knowledge when exposing the other potential problems mentioned by group 1 students. These students

Excerpt 3 Teachers' increased their possibility knowledge when they were exposed to the students' ideas of supportive mobile phone use

\footnotetext{
Eva: So, if they document stuff it's a great help when grading them as we can't be with them everywhere. It would actually be great if they could show their work in a PowerPoint file or something similar.

Johanna: I think this different kind of approach could make better use of a visit this if we did it this way next time.
} 
Excerpt 4 Teachers' increased their possibility knowledge when they were exposed to the students' ideas of supportive mobile phone use

Johanna: It could be an idea that they should document.

Eva: $\quad$ Yes, because then you can see what they have done.

Johanna: So, we need some task with the criterion that the students should show something. Communication or something like that.

Eva: $\quad$ Communicate what they have done.

Johanna: If a student does a task, we could use it in a new way when we grade their work.

Eva: That's right, and I think we should be able to get help.

Johanna: There's no doubt it would help us with our grading.

argued that the possibility of using mobile phones during lectures could cause problems if the use divert attention from the teacher's speaking. The students also stated that searching for information could be a problem if they had to pay for the cost of data themselves. Furthermore, the teachers did not respond to the group 2 students' comment that mobile phones have limited capacity. The students stated that mobile phones have less capacity than computers and that when students use computers during study visits, they have less need for mobile phones. The students also expressed that mobile phones could give them less credible information compared to books.

\section{Discussion}

\subsection{The influence on teachers' possibility knowledge}

The results describe how the teachers' possibility knowledge is influenced when they are exposed to students' ideas on how mobile phones could be both supportive and problematic in school activities. The teachers then increased their possibility knowledge on five occasions (see Fig. 1).

Excerpt 5 Teachers' increased their possibility knowledge when they were exposed to the students' ideas of supportive mobile phone use

Eva: How does the learning management system work? Is it totally unprotected if they upload stuff? Is it closed to the public or can anyone access it and look at it - or only those who are part of the group? I don't think it's a good idea to upload anything.

Johanna: Yes, exactly.

Eva: $\quad$ Because of our integrity and so on. And that they mustn't download it and share it. I'm thinking they might share it on YouTube or somewhere.

Johanna: Yes, that's something that needs to be checked. It shouldn't be possible to download and save the videos and upload them somewhere else.

Eva: It would be unfortunate if they happened to record a moment when we were angry and then uploaded it somehow.

Johanna: Yes, exactly. 
Excerpt 6 Students' ideas on rules and the researcher's description to teachers of the problems the students wanted to regulate

\begin{tabular}{l}
$\begin{array}{l}\text { Note from student } \\
\text { group 2: }\end{array}$ \\
$\begin{array}{l}\text { In the mobile phones. } \\
\text { Researcher: }\end{array}$ \\
$\begin{array}{l}\text { were used to photograph and film someone who didn't want to be photographed } \\
\text { or filmed. }\end{array}$ \\
\hline
\end{tabular}

The teachers' increased possibility knowledge of supportive mobile phone use. The teachers increased their possibility knowledge when they were exposed to the students' idea that mobile phone use could support the students' division of labor, when they want to communicate experiences with each other, independently of place and time. Previously, the teachers' design ideas have not indicated that the students' networked mobile phone use could support their school activities (Kearney et al. 2015). The teachers' increased possibility knowledge that LMS could support the students' communication between different locations are reminiscent of studies that have seen teachers increase their insights into students' online use (Hsieh and Tsai 2017; Kearney et al. 2015; Zurita and Nussbaum 2007). Unlike this previous research, the teachers in this pilot study have not increased their understanding because of their experiences or because of the students' ownership of mobile phones. In contrast to previous research, the teachers did not increase their understanding because of their personal use, students' personal ownership of mobile phones, or pleasant, stimulating and enjoyable use (Adukaite et al. 2017; Kearney et al. 2015; O'Bannon and Thomas 2015; O'Neill et al. 2018). Instead, these results show that the teachers' increased possibility knowledge was stimulated by the students' suggestions. Thus, the teachers increased their understanding of how features such as LMS, notes, photographs and videos could be used supportively, for both the students' and the teachers' division of labor.

The students' ideas also stimulated the teachers to understand that photographs could be used in combination with presentation programs. This is in order to support the teachers' division of labor when grading the students' knowledge in relation to the syllabus. Thus, there are similarities to research that indicate that teachers are influenced by the fact that students' mobile phone use is in accordance with the syllabus (Adukaite et al. 2017; Hsieh and Tsai 2017). The results also show that the teachers want to design the activity with new student tasks in order to reach the object of the activity. Thus, stimuli from students have increasing the teachers' possibility knowledge on how tasks may need to be designed to provide students with mobile phone use

Excerpt 7 Teachers' increased their possibility knowledge when they were exposed to the students' ideas of problematic mobile phone use

Johanna: Well, we could hang onto them and then distribute them later. "Now you can use it." Then you control the issue of not being video recorded.

Eva: $\quad$ Yes, exactly. 


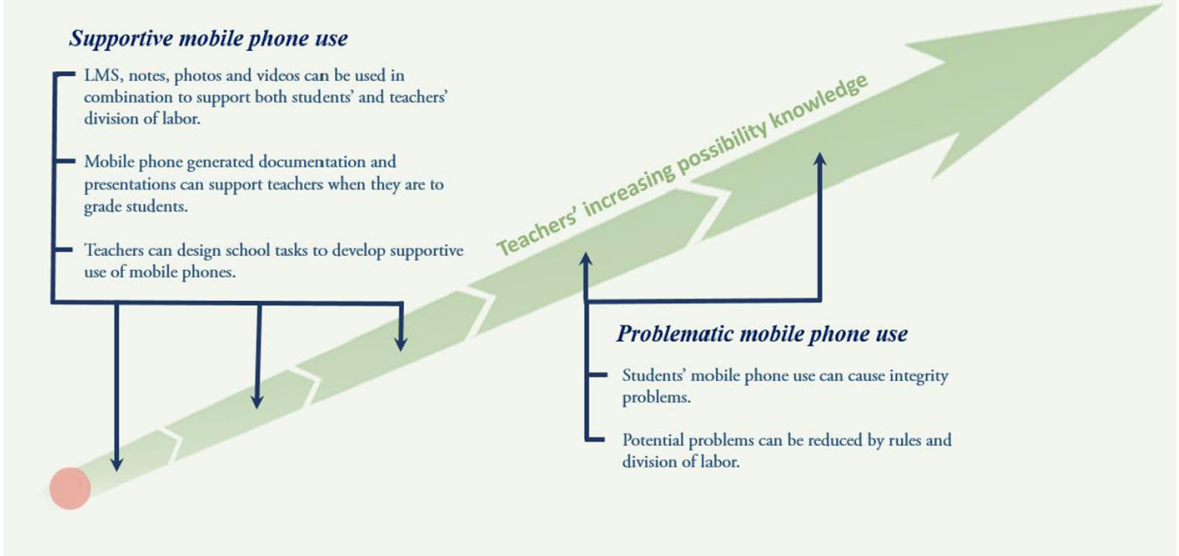

Fig. 1 The influence on teachers' possibility knowledge when they were exposed to students' ideas on how mobile phones could be both supportive and problematic in school activities

in order to support their collaborative actions and the teachers' ability to grade the students' work. The finding is similar to research that has pointed out that teacher education can help teachers understand how to change their pedagogy (Khaddage et al. 2015; Peng et al. 2009). There are also similarities with research that discusses the possibility of increasing teachers' understanding by showing effective ways of using mobile phones (O'Neill et al. 2018).

The teachers' increased their possibility knowledge of problematic mobile phone use As the teachers were exposed to the students' suggestions, that students should use video and LMS, the teachers increased their possibility knowledge of potential problems. Although the teachers first got a new vision that LMS could support the students' communication of experiences, they wanted to limit the students' access to the tool. The reason for limiting the students' mobile phone use was the teachers' increased concerns regarding how such use could cause problems (Dinsmore 2019; JoyceGibbons et al. 2018; Nikolopoulou and Gialamas 2018; O'Bannon and Thomas 2015). Thus, the students' ideas stimulated the teachers' possibility knowledge of how the students' use of video in combination with LMS could cause a division of labor in which teachers could be insulted. Unlike previous research, this pilot study does not show that teachers' concerns increased because of the students' increased access to mobile phones (O'Bannon and Thomas 2015). Sung et al. (2017) propose that problems with the division of labor and rules in school activities could be resolved with more technology-based assistance. However, in this pilot study, it appears that teachers want to increase their understanding of LMS features further, before they allow use. First, they want to find out how the application could cause problems for the teachers' division of labor. When the teachers then considered the students' suggestions regarding how problematic mobile phone use could be limited, they wanted to limit the risk of problems arising through increased control (Dinsmore 2019; Sung et al. 2017). In the same way as the students' ideas, the teachers would like to have a division of labor and be responsible for when students have access to their mobile phones. In this way, the teachers have 
increased their possibility knowledge about how problematic mobile phone use could be limited in school activities in relation to the students' ideas.

\subsection{Similarities and differences between ideas that have, or have not, influenced teachers' possibility knowledge}

Although teachers increased their possibility knowledge on several occasions, there were also stimuli that did not lead to an increased understanding. The results show that there are similarities and differences between the students' ideas that have, and have not, increased the teachers' possibility knowledge on mobile phone use. All the stimuli that did not increase the teachers' possibility knowledge have similarities because they describe how the use of mobile phones could both support and cause problems for the students' division of labor. The stimuli that increased the teachers' possibility knowledge have similarities insofar as the teachers have largely discussed the students' suggestions in relation to how they could both support or cause problems for the teachers' division of labor. In other words, the difference between the stimuli that have, and have not, increased the teachers' possibility knowledge is largely rooted in whether the teachers have transformed the students' ideas in relation to their own division of labor. The results are reminiscent of O'Neill et al. (2018), who found that teachers' willingness to implement mobile phones is more influenced by the teachers' personal objectives than their ideas on how mobile phones could be used for didactic purposes.

\section{Conclusion and pedagogical implications}

The teachers' possibility knowledge was influenced by the students' ideas in many ways. They have increased their understanding on five occasions regarding how mobile phones could be used supportively and how mobile phone use could cause problems when exposing the students' ideas. The results also show that there are similarities and differences between the students' ideas that have, and have not, influenced the teachers' possibility knowledge. In summary, the pilot study contributes to the following answers to the aim and research questions:

- Teachers have increased their possibility knowledge on which mobile phone features could be used to support the students' schoolwork

- Teachers have increased their possibility knowledge on how tasks involving mobile phone features could be designed to support the students' schoolwork

- Teachers have increased their possibility knowledge of how the students' use of mobile phone features could support the teachers' division of labor

- Teachers have increased their possibility knowledge of the potential problems that the use of different mobile phone features could cause for school activities

- Teachers have increased their possibility knowledge of the potential problems that may need to be regulated and how rules and the division of labor could limit such problems

- Teachers have largely not increased their possibility knowledge when they have not related the students' ideas to their own division of labor 
- The students' ideas that have increased the teachers' possibility knowledge have similarities because, to a greater extent than the other ideas, they have been transformed in relation to the teachers' division of labor. This is also what distinguishes the students' ideas that have, and have not, increased the teachers' possibility knowledge

The results show that several of the students' ideas of mobile phone use have stimulated the teachers. As a result, the teachers and the students have gained a more common motive of how mobile phones could be used to support the object of the activity, and the potential problems they may need to limit through rules and a division of labor. In this way, the pilot study adds important knowledge about how teachers' understanding could increase when they are exposed to the students' ideas about how mobile phones could be used and limited in school activities. This knowledge is needed since previous research has emphasized the importance of reducing the differences between students' and teachers' different ideas of mobile phone use (Ariel and Elishar-Malka 2019). It has also been shown that it is necessary to develop teachers' insights into mobile phone use (Ariel and Elishar-Malka 2019; Hsieh and Tsai 2017). Despite this, surprisingly few studies have investigated how teachers' understanding of mobile phone use could be increased in relation to students (Dinsmore 2019; Muñoz-Cristóbal et al. 2017; Osakwe et al. 2017). Previous research has stressed the possibility of increasing the teachers' knowledge through teacher education on how mobile phones could be integrated into teaching (Adukaite et al. 2017; Birgin et al. 2019; Hsieh and Tsai 2017). These results provide increased understanding of how stimuli from students have the potential to increase teachers' possibility knowledge, which may have the potential to complement to practical experience and teacher education when designing school activities.

\section{Limitations and future work}

This pilot study contributes to qualitative results on how teachers' knowledge increases during the design process, as requested by previous research (Chai et al. 2017; Crompton et al. 2017). However, qualitative studies are limited in their sample selection, meaning more research is needed to confirm the results. Thus, continued research is important in order to relate these qualitative results to a larger context. Although this pilot study offers important knowledge, it also shows the challenges and limitations that require further research.

This pilot study shows the challenges insofar as teachers largely transform the students' ideas if they can relate the ideas to their own division of labor. Thus, there is a risk that the results will not be as fully student-centered as the students' initial visions. Since successful mobile phone use requires an understanding of what feature is most suitable from the students' perspective (Khaddage et al. 2015; Kukulska-Hulme and Traxler 2007), more research is needed on how stimuli can be used to increase teachers' insights into the issue at hand. This means that future research must focus on how teachers can increase their understanding, even if this does not benefit the teachers' division of labor. It is also important to gain a better understanding of why teachers are not stimulated by certain ideas. Continued understanding is important because students may consider that mobile phones are useful for schoolwork while 
teachers consider such use to be a problem (Fernandez 2018; Ott et al. 2018). Continuing knowledge is also important because of the risk that teachers limit mobile phone use in a way that leads to opposition from students (Dinsmore 2019; Fernandez 2018; Gentina et al. 2018; Ott et al. 2018). Students could also use their mobile phones illegally if teachers and students do not share similar ideas (Joyce-Gibbons et al. 2018; Nikolopoulou and Gialamas 2018; Ott et al. 2018). In order to resolve the problems, teachers and students must share a common object for a school activity and agree on how mobile phones should be used, regulated and how the work should be distributed between teachers and students (Engeström 1999, 2000).

At present, CHAT does not have enough theoretical keys for understanding why teachers are not stimulated by certain ideas. Thus, one suggestion is to develop the theoretical framework in order to increase the teachers' possibility knowledge. For this, the theoretical framework must focus more on why people reject or do not adopt certain ideas. This development is important in order to be able to use stimuli in a way that further reduces the differences between students' and teachers' ideas. Hopefully, the problems associated with mobile phone use in school activities use can then be reduced (Ariel and Elishar-Malka 2019; Dinsmore 2019; Muñoz-Cristóbal et al. 2017).

Funding Information Open access funding provided by Royal Institute of Technology.

Open Access This article is licensed under a Creative Commons Attribution 4.0 International License, which permits use, sharing, adaptation, distribution and reproduction in any medium or format, as long as you give appropriate credit to the original author(s) and the source, provide a link to the Creative Commons licence, and indicate if changes were made. The images or other third party material in this article are included in the article's Creative Commons licence, unless indicated otherwise in a credit line to the material. If material is not included in the article's Creative Commons licence and your intended use is not permitted by statutory regulation or exceeds the permitted use, you will need to obtain permission directly from the copyright holder. To view a copy of this licence, visit http://creativecommons.org/licenses/by/4.0/.

\section{References}

Adukaite, A., van Zyl, I., Er, Ş., \& Cantoni, L. (2017). Teacher perceptions on the use of digital gamified learning in tourism education: The case of south African secondary schools. Computers \& Education, $111,172-190$.

Ariel, Y., \& Elishar-Malka, V. (2019). Learning in the smartphone era: Viewpoints and perceptions on both sides of the lectern. Education and Information Technologies, 1-12.

Birgin, O., Uzun, K., \& Akar, S. G. M. (2019). Investigation of Turkish mathematics teachers' proficiency perceptions in using information and communication technologies in teaching. Education and Information Technologies, 1-21.

Chai, C. S., Tan, L., Deng, F., \& Koh, J. H. L. (2017). Examining pre-service teachers' design capacities for web-based 21st century new culture of learning. Australasian Journal of Educational Technology, 33(2).

Chung, C.-J., Hwang, G.-J., \& Lai, C.-L. (2019). A review of experimental mobile learning research in 20102016 based on the activity theory framework. Computers \& Education, 129, 1-13.

Cohen, L., Manion, L., \& Morrison, K. (2007). Research methods in education. London: Routledge.

Crompton, H., Burke, D., \& Gregory, K. H. (2017). The use of mobile learning in PK-12 education: A systematic review. Computers \& Education, 110, 51-63.

Dalkey, N., \& Helmer, O. (1963). An experimental application of the Delphi method to the use of experts. Management Science, 9(3), 458-467.

Delp, P., Thesen, A., Motiwalla, J., \& Seshardi, N. (1977). Nominal group technique. System Tools Project Plan, 1, 14-18. 
Denscombe, M. (2014). The good research guide: for small-scale social research projects. London: McGrawHill Education.

Dinsmore, B. (2019). Contested affordances: Teachers and students negotiating the classroom integration of mobile technology. Information, Communication \& Society, 22(5), 664-677.

Dixit, S., Shukla, H., Bhagwat, A. K., Bindal, A., Goyal, A., Zaidi, A. K., \& Shrivastava, A. (2010). A study to evaluate mobile phone dependence among students of a medical college and associated hospital of Central India. Indian Journal of Community Medicine: Official Publication of Indian Association of Preventive \& Social Medicine, 35(2), 339-341.

Elliott, R., Fischer, C. T., \& Rennie, D. L. (1999). Evolving guidelines for publication of qualitative research studies in psychology and related fields. British Journal of Clinical Psychology, 38(3), 215-229.

Ellis, V., Gower, C., Frederick, K., \& Childs, A. (2015). Formative interventions and practice-development: A methodological perspective on teacher rounds.

Engeström, Y. (1987). Learning by expanding: An activity-theoretical approach to developmental research. Orienta-Konsultit: Helsinki.

Engeström, Y. (1990). Learning, working and imagining: Twelve studies in activity theory: Orienta-konsultit.

Engeström, Y. (1999). Expansive visibilization of work: An activity-theoretical perspective. Computer Supported Cooperative Work (CSCW), 8(1-2), 63-93.

Engeström, Y. (2000). Activity theory as a framework for analyzing and redesigning work. Ergonomics, 43(7), $960-974$.

Engeström, Y. (2004). New forms of learning in co-configuration work. Journal of Workplace Learning, $16(1 / 2), 11-21$.

Engeström, Y. (2011). From design experiments to formative interventions. Theory \& Psychology, $21,598$. https://doi.org/10.1177/0959354311419252.

Engeström, Y., \& Sannino, A. (2010). Studies of expansive learning: Foundations, findings and future challenges. Educational Research Review, 1(5), 1-24.

Engeström, Y., \& Sannino, A. (2016). Expansive learning on the move: Insights from ongoing research/El aprendizaje expansivo en movimiento: Aportaciones de la investigación en curso. Infancia y Aprendizaje, 39(3), 401-435.

Engeström, Y., Pasanen, A., Toiviainen, H., \& Haavisto, V. (2005). Expansive learning as collaborative concept formation at work. New learning challenges: Going beyond the industrial age system of school and work, 47-77.

Engeström, Y., Sannino, A., \& Virkkunen, J. (2014). On the methodological demands of formative interventions. Mind, Culture, and Activity, 21(2), 118-128.

Fernandez, S. (2018). University Student's perspectives on using cell phones in classrooms-are they dialing up disaster? Turkish Online Journal of Educational Technology-TOJET, 17(1), 246-258.

Gentina, E., Tang, T. L.-P., \& Dancoine, P.-F. (2018). Does gen Z's emotional intelligence promote iCheating (cheating with iPhone) yet curb iCheating through reduced nomophobia? Computers \& Education, 126, 231-247.

Hakkarainen, K. (2009). A knowledge-practice perspective on technology-mediated learning. International Journal of Computer-Supported Collaborative Learning, 4(2), 213-231.

Hamel, J. (2001). The focus group method and contemporary French sociology. Journal of Sociology, 37(4), $341-353$.

Horton, J. (1980). Nominal group technique: A method of decision-making by committee. Anaesthesia, 35(8), $811-814$.

Hsieh, W.-M., \& Tsai, C.-C. (2017). Taiwanese high school teachers' conceptions of mobile learning. Computers \& Education, 115, 82-95.

Joyce-Gibbons, A., Galloway, D., Mollel, A., Mgoma, S., Pima, M., \& Deogratias, E. (2018). Mobile phone use in two secondary schools in Tanzania. Education and Information Technologies, 23(1), 73-92.

Kearney, M., Burden, K., \& Rai, T. (2015). Investigating teachers' adoption of signature mobile pedagogies. Computers \& Education, 80, 48-57.

Khaddage, F., Christensen, R., Lai, W., Knezek, G., Norris, C., \& Soloway, E. (2015). A model driven framework to address challenges in a mobile learning environment. Education and Information Technologies, 20(4), 625-640.

Kim, H. J., \& Jang, H. Y. (2015). Factors influencing students' beliefs about the future in the context of tabletbased interactive classrooms. Computers \& Education, 89, 1-15.

Kukulska-Hulme, A., \& Traxler, J. (2007). Designing for mobile and wireless learning. Rethinking pedagogy for a digital age: Designing and delivering e-learning, 180-192.

Lindell, T. L., (2018). Erfarenheter och potentiella transformationer: Lärare och elever beskriver hur mobiltelefoner kan användas för skoluppgifter (Doctoral dissertation, KTH). 
Lindell, T. L., \& Hrastinski, S. (2018). Exploring functions and tenable structures for Mobile use as support for school tasks. In Mobile and Ubiquitous Learning (pp. 323-339). Springer, Singapore.

Lorenzo, M. F., \& Trujillo, C. M. (2018). Cognitive processes, ICT, and education: A critical analysis. Computers in the Schools, 35(3), 186-203.

Mathison, S. (1988). Why triangulate? Educational Researcher, 17(2), 13-17.

Muñoz-Cristóbal, J. A., Gallego-Lema, V., Arribas-Cubero, H. F., Martínez-Monés, A., \& Asensio-Pérez, J. I. (2017). Using virtual learning environments in bricolage mode for orchestrating learning situations across physical and virtual spaces. Computers \& Education, 109, 233-252.

Nikolopoulou, K., \& Gialamas, V. (2018). Mobile phone dependence: Secondary school pupils' attitudes. Education and Information Technologies, 23(6), 2821-2839.

O'Bannon, B. W., \& Thomas, K. M. (2015). Mobile phones in the classroom: Preservice teachers answer the call. Computers \& Education, 85, 110-122.

O'Neill, S., Kreijns, K., \& Vermeulen, M. (2018). Factors influencing Teachers' intentions to integrate smartphones in language lessons. JALT CALL Journal, 14(2), 91-117.

Osakwe, J., Dlodlo, N., \& Jere, N. (2017). Where learners' and teachers' perceptions on mobile learning meet: A case of Namibian secondary schools in the Khomas region. Technology in Society, 49, 16-30.

Ott, T., Magnusson, A. G., Weilenmann, A., \& af Segerstad, Y. H. (2018). "It must not disturb, it's as simple as that": Students' voices on mobile phones in the infrastructure for learning in Swedish upper secondary school. Education and Information Technologies, 23(1), 517-536.

Peng, H., Su, Y. J., Chou, C., \& Tsai, C. C. (2009). Ubiquitous knowledge construction: Mobile learning redefined and a conceptual framework. Innovations in Education and Teaching International, 46(2), 171183.

Sannino, A., \& Engeström, Y. (2017). Co-generation of societally impactful knowledge in change laboratories. Management Learning, 48(1), 80-96.

Sannino, A., Engeström, Y., \& Lemos, M. (2016). Formative interventions for expansive learning and transformative agency. Journal of the Learning Sciences, 25(4), 599-633.

Spencer, L., Ritchie, J., Lewis, J., \& Dillon, L. (2003). Quality in qualitative evaluation: A framework for assessing research evidence.

Sung, Y.-T., Yang, J.-M., \& Lee, H.-Y. (2017). The effects of mobile-computer-supported collaborative learning: Meta-analysis and critical synthesis. Review of Educational Research, 87(4), 768-805.

Stewart, D. W., \& Shamdasani, P. N. (2014). Focus groups: Theory and practice (Vol. 20). Thousand Oaks: Sage publications

Swedish Research Council, (2019, August 23). Rules and guidelines for research. Retrieved August 23, 2019, from http://www.codex.vr.se/index.shtml

Timmis, S. (2014). The dialectical potential of cultural historical activity theory for researching sustainable CSCL practices. International Journal of Computer-Supported Collaborative Learning, 9(1), 7-32.

Tong, A., Sainsbury, P., \& Craig, J. (2007). Consolidated criteria for reporting qualitative research (COREQ): A 32-item checklist for interviews and focus groups. International Journal for Quality in Health Care, 19(6), 349-357.

Twining, P., Heller, R. S., Nussbaum, M., \& Tsai, C.-C. (2017). Some guidance on conducting and reporting qualitative studies: Elsevier.

Ven, A. H. V. D., \& Delbecq, A. L. (1974). The effectiveness of nominal, Delphi, and interacting group decision making processes. Academy of Management Journal, 17(4), 605-621.

Yildirim, C., Sumuer, E., Adnan, M., \& Yildirim, S. (2016). A growing fear: Prevalence of nomophobia among Turkish college students. Information Development, 32(5), 1322-1331.

Yin, R. K. (2013). Validity and generalization in future case study evaluations. Evaluation, 19(3), 321-332.

Zurita, G., \& Nussbaum, M. (2007). A conceptual framework based on activity theory for mobile CSCL. British Journal of Educational Technology, 38(2), 211-235.

Publisher's note Springer Nature remains neutral with regard to jurisdictional claims in published maps and institutional affiliations. 